\title{
Phase I Trial of Copanlisib, a Selective Pi3k Inhibitor, in Combination With Cetuximab in Patients With Recurrent and/or Metastatic Head and Neck Squamous Cell Carcinoma
}

\section{Grégoire Marret}

Institut Curie

Nicolas Isambert

CHU Poitiers: Centre Hospitalier Universitaire de Poitiers

Keyvan Rezai

Institut Curie

Jocelyn Gal

Centre Antoine-Lacassagne

\section{Esma Saada-Bouzid}

Centre Antoine-Lacassagne

\section{Frédéric Rolland}

Centre René Gauducheau: Institut de Cancerologie de l'Ouest

\section{Maggy Chausson}

UNICANCER

\section{Edith Borcoman}

Institut Curie

Marie Alt

Institut Curie

Jerzy Klijanienko

Institut Curie

\section{Damien Vansteene}

Institut de Cancérologie de l'Ouest: Institut de Cancerologie de l'Ouest

Joël Guigay

UNICANCER

Maud Kamal

Institut Curie

Ivan Bièche

Institut Curie

Christophe LeTourneau ( $\sim$ Christophe.LeTourneau@curie.fr) 


\section{Research Article}

Keywords: Cetuximab, copanlisib, EGFR, head and neck cancer, phase I, Phosphatidylinositol-3 kinase (PI3K)

Posted Date: June 18th, 2021

DOI: https://doi.org/10.21203/rs.3.rs-594391/v1

License: (a) (1) This work is licensed under a Creative Commons Attribution 4.0 International License. Read Full License

Version of Record: A version of this preprint was published at Investigational New Drugs on July 28th, 2021. See the published version at https://doi.org/10.1007/s10637-021-01152-z. 


\section{Abstract}

\section{Background}

The phosphatidylinositol-3 kinase pathway is often altered in head and neck squamous cell carcinoma (HNSCC), and is involved in the resistance to EGFR inhibitors.

\section{Objective}

We investigated the dose-limiting toxicities (DLTs), maximum tolerated dose, pharmacokinetics, and preliminary efficacy of the combination of copanlisib, an intravenous, pan-class I PI3K inhibitor, with the anti-EGFR monoclonal antibody cetuximab in recurrent and/or metastatic HNSCC patients in a phase I dose-escalation trial.

\section{Patients and methods}

Copanlisib was given intravenously on days 1,8, and 15 of 28-day cycles at the dose of $45 \mathrm{mg}$ and 30 $\mathrm{mg}$, in combination with standard doses of weekly cetuximab $\left(400 \mathrm{mg} / \mathrm{m}^{2}\right.$ loading dose followed by 250 $\mathrm{mg} / \mathrm{m}^{2}$ on days 8,15 , and 22 , and weekly thereafter).

\section{Results}

Three patients received copanlisib $45 \mathrm{mg}$, of whom two experienced grade 3 hyperglycemia during Cycle 1 that met the DLT criteria. Eight patients were then treated with copanlisib at the dose of $30 \mathrm{mg}$. Because of the occurrence of hyperglycemia, a premedication with metformine was introduced on the day of the injections. No DLTs were reported at this dose level. The trial was stopped early because of the unfavourable toxicity profile of the combination. Among eight evaluable patients for response, four patients $(50 \%)$ had disease stabilization according to RECIST1.1 as best response.

\section{Conclusion}

Copanlisib combined with cetuximab demonstrated unfavorable toxicity and limited efficacy in heavily pretreated recurrent and/or metastatic HNSCC patients. NCT02822482, Date of registration: June 2016.

\section{Introduction}

Head and neck squamous cell carcinoma (HNSCC) is the seventh most common cancer worldwide [1]. Early-stage disease can be successfully treated with a single-modality treatment, including surgery or radiotherapy [2]. Treatment options for locally advanced disease include upfront surgery followed by adjuvant (chemo)radiotherapy depending on the pathological features, exclusive chemoradiotherapy, and induction chemotherapy for organ preservation followed by either (chemo)radiotherapy or surgery followed by (chemo)radiotherapy depending on response to induction chemotherapy [2]. Around $50 \%$ of locally advanced HNSCC patients recur after primary treatment, at the locoregional level and/or with 
distant metastases [3]. Patients who are not amenable to local treatments have a dismal prognosis (i.e. 6 to 9 months in the absence of treatment) [4]. In the recurrent and/or metastatic setting, first-line standardof-care therapy include immunotherapy with anti-PD1 agents as single agent or in combination with chemotherapy in most of cases [5-7], whereas the combination of cetuximab, an anti-EGFR monoclonal antibody, with chemotherapy remains the standard of care for PD-L1 non-expressing tumors $[8,9]$.

The phosphatidylinositol-3 kinase (PI3K) signaling pathway has been found to play an important role in the pathogenesis of HNSCC $[10,11]$. Both PIK3CA activating mutations and amplifications were reported in $13 \%$ and $22 \%$ of HNSCC patients, respectively [12]. The H1047R/L activating mutation has been shown to overcome the EGFR inhibition through unrestrained AKT phosphorylation in preclinical HNSCC cell lines [13]. PI3K inhibition has also been shown to restore sensitivity to cetuximab in EGFR-resistant HNSCC models both in vitro and in vivo [14]. In the clinic, PI3K inhibition with buparlisib improved overall survival in combination with paclitaxel as compared to paclitaxel alone in recurrent and/or metastatic HNSCC patients [15].

Copanlisib (BAY 80-6946) is a highly selective, pan-class, PI3K inhibitor with potent activity against both the $\alpha$ and $\delta$ catalytic subunit isoforms. A first-in-human phase I study established the maximum tolerated dose of copanlisib single-agent as $60 \mathrm{mg}$ [16]. Copanlisib demonstrated a manageable safety profile in long-term treatment in lymphoma, with transient hyperglycemia (50\%), diarrhea (35\%), transient hypertension (30\%), and neutropenia (30\%) being the most common adverse events (AEs) [17]. Copanlisib was shown to overcome resistance to cetuximab in vivo [18].

We report here the results of the phase I clinical trial of copanlisib combined with cetuximab in patients with recurrent and/or metastatic HNSCC who failed platinum and cetuximab therapy.

\section{Patients And Methods}

\section{Study design and treatment}

This study was an open-label, non-randomized, dose escalation phase I clinical trial conducted between April 26, 2016 and August 17, 2019 in four centers in France. Intravenous copanlisib was administered over one hour, on days 1,8 , and 15 of 28-day cycles. Cetuximab was administered intravenously at a loading dose of $400 \mathrm{mg}$ per square meter of body-surface area one hour after copanlisib, followed by subsequent weekly doses of $250 \mathrm{mg}$ per square meter. Dose escalation followed a $3+3$ design. A starting dose of $75 \%$ ( $45 \mathrm{mg}$ ) of its recommended phase II dose as single agent $(60 \mathrm{mg})$ was selected for copanlisib, whereas, cetuximab was given at its full recommended phase II dose. Dose level two was supposed to be the recommended phase II doses of both copanlisib and cetuximab given as single agents. A dose level - 1 with copanlisib given at the dose of $30 \mathrm{mg}$ was planned if needed.

The main discontinuation criteria included patient request, disease progression, dose interruption lasting more 21 days of any agent, pregnancy, and unacceptable toxicity. 
The study was compliant with the Declaration of Helsinki and Good Clinical Practice, and was approved by the appropriate ethics committees. All patients provided written informed consent. This study was registered under identifier NCT02822482 in ClinicalTrials.gov.

\section{Patients}

Patients aged $\geq 18$ years with recurrent and/or metastatic histologically or cytologically confirmed HNSCC of the oral cavity, oropharynx, larynx, or hypopharynx, defined as distant metastases and/or inoperable local and/or regional recurrence, were eligible. Eligible patients were required to have disease progression on or after cetuximab and platinum therapy (cisplatin or carboplatin). Patients had to have at least one evaluable lesion according to RECIST1.1, an Eastern Cooperative Oncology Group performance status of $\leq 2$, adequate bone marrow (absolute neutrophil count [ANC] $\geq 1.0 \times 10^{9} / \mathrm{L}$, platelets $\geq$ $75 \times 10^{9} / \mathrm{L}$ ), and organ functions (ALT/AST $\leq 2.5 \times$ upper limit of normal [ULN], bilirubin $\leq 1.5 \times U L N$, creatinine clearance $\geq 60 \mathrm{~mL} / \mathrm{min}$ as measured or calculated by Cockcroft and Gault formula, or serum creatinine $\leq \mathrm{ULN}$ ). Patients with uncontrolled diabetes mellitus were excluded.

\section{Endpoints}

The primary endpoint of the study was the occurrence of dose-limiting toxicities (DLTs) during Cycle 1 to define the maximum tolerated dose (MTD) of the combination. Secondary endpoints included safety, the pharmacokinetics parameters, the assessment of potential predictive biomarkers, overall response rate (ORR), progression-free survival (PFS), and overall survival (OS).

\section{Assessments}

\section{Safety and tolerability}

Adverse events (AEs) were evaluated and graded according to the National Cancer Institute Common Terminology Criteria for Adverse Events version 4.03. DLTs were defined as grade $\geq 3$ hyperglycemia despite curative optimal glucose lowering therapy, grade $\geq 3$ ALT/AST elevation, ANC $<0.5 \times 10^{9} / \mathrm{L}$ lasting more than seven days, bleeding felt to be due to thrombocytopenia, febrile neutropenia (both ANC < $1.0 \times 10^{9} / \mathrm{L}$ and fever $>38.5^{\circ} \mathrm{C}$ ), platelets $<25 \times 10^{9} / \mathrm{L}$, diarrhea $\geq$ grade 3 , rash $\geq$ grade 4 , hypertension $\geq$ grade 3 despite optimal treatment, and any clinically significant $\geq$ grade $3 \mathrm{AE}$ related to copanlisib and/or cetuximab.

\section{Pharmacokinetics}

Blood samples were collected at Cycle 1 Day 1 and at Cycle 1 Day 15. A method was developed and validated for the determination of copanlisib in human plasma samples with heparinate at the Department of Radio-Pharmacology of the Institut Curie, using protein precipitation for sample preparation followed by Ultra Performance Liquid Chromatography with Tandem Mass Spectrometric Detection. This method was validated over the concentration range $1.00 \mathrm{ng} / \mathrm{mL}$ to $600 \mathrm{ng} / \mathrm{mL}$. 
Copanlisib individual pharmacokinetics parameters were calculated using plasma concentration-time data by non-compartmental analysis. The maximum plasma concentration $\left(\mathrm{C}_{\max }\right)$, and time to reach $\mathrm{C}_{\max }\left(\mathrm{T}_{\max }\right)$ were presented. The area under the plasma concentration-time curve (AUC) from 0 to the last measurable plasma concentration $\left(\mathrm{AUC}_{0}\right.$ - last $)$ was calculated by the linear trapezoidal rule. AUC extrapolated to infinity $\left(\mathrm{AUC}_{0-\infty}\right)$ was calculated as $\mathrm{AUC}_{0-\infty}=\mathrm{AUC}_{0-\text { last }}+\mathrm{Ct} / \lambda z$, where $\mathrm{Ct}$ was the last measurable plasma concentration, and $\lambda z$ the apparent terminal phase rate constant. The apparent plasma terminal elimination half-life $t_{1 / 2}$ was estimated using $t_{1 / 2}=(\ln 2) / \lambda z$.

A population pharmacokinetics modelling was performed in order to describe copanlisib plasma concentrations versus time curves. The pharmacokinetics of copanlisib was best described by a twocompartment open model with linear elimination. Different covariates were investigated, including both body weight and age as a continuous covariate.

\section{Exploratory analyses}

For all patients, a fresh frozen research biopsy or Formalin fixed paraffin embedded (FFPE) archived tumour sample was required for biomarker analyses.

The tumour samples were analysed with a custom gene panel that included exons 10, 14, and 21 of PIK3CA, as well as the total coding sequence of PTEN allowing the detection of gene copy number alterations in addition to mutations (Supplementary Materials and Methods). For the tested oncogenes including PIK3CA, only pathogenic variants driving a gain of function and amplifications were considered, whereas for tumour suppressor genes such as PTEN, pathogenic variants driving a loss of function were considered.

Immunohistochemistry (IHC) was performed in parallel to determine the expression level of PTEN, and to validate any PTEN loss of function. A monoclonal antibody specific of the PTEN amino acids 321 to 336 was used (Zymed $\AA$ laboratories).

\section{Efficacy}

ORR and PFS were determined using RECIST1.1. The target lesions were measured by computed tomography or magnetic resonance imaging at baseline within 28 days before enrolment, and every eight weeks after starting administration. PFS was defined as the time between inclusion and disease progression or death, whichever occurred first. OS was defined as the time between inclusion and death due to any cause. Patients showing no event (death or disease progression) or lost to follow-up were censored at the date of their last contact. ORR was defined as the proportion of evaluable patients for response with a complete or a partial response according to RECIST1.1.

\section{Statistical analysis}

The planned sample size for the dose escalation included a maximum of 12 patients. Safety analyses were performed on the full analysis set. Pharmacokinetic parameters were calculated according to the Loading [MathJax]/jax/output/CommonHTML/fonts/TeX/fontdata.js e performed using $\chi 2$ test or Fisher's exact test 
for categorical data, Student's test or Wilcoxon's test for continuous variables and log-rank test for censured data. OS and PFS were estimated using the Kaplan-Meier method. Median follow-up with a 95\% confidence interval was calculated by reverse Kaplan-Meier method. ORR was calculated on the subgroup of evaluable patients for response according to RECIST1.1.

All analyses were performed with SAS V 9.4 and R 3.6.1 software on Windows. For clinical and biological analyses, all p-values $<0.05$ (two-sided) were considered statistically significant.

\section{Results}

\section{Patients and treatment}

Eleven patients were enrolled in the trial (three at the dose level of $45 \mathrm{mg}$, and eight at the dose level of 30 mg) (Fig. 1). Median age was 59 years [range: 55-77] (Table 1). All patients were male. Most frequent primary tumor location was oropharynx in five patients (45\%). Two out of the five patients (40\%) with oropharyngeal HNSCC were HPV-positive. Three patients (27\%) had a locoregional recurrence only, six $(55 \%)$ only distant metastases, and two $(18 \%)$ both a locoregional recurrence and distant metastases at study entry. The median number of prior lines of systemic treatment in the recurrent and/or metastatic setting was two [range: 2-5]. Nine patients were tested for PIK3CA activating mutations and PTEN loss (inactivating mutations by NGS and/or loss of protein expression by $\mathrm{IHC}$ ). One patient harboured both a PIK3CA E542K hotspot mutation (c.1624G > A) and a loss of PTEN protein expression, and one patient harboured a sole loss of PTEN protein expression. 
Table 1

Patient characteristics

\begin{tabular}{|c|c|}
\hline Characteristics & $N=11$ \\
\hline \multicolumn{2}{|l|}{ Sex, n (\%) } \\
\hline Male & $11(100)$ \\
\hline \multicolumn{2}{|l|}{ Age, years } \\
\hline Median [range] & 59 [55-77] \\
\hline \multicolumn{2}{|l|}{ Performance status, n (\%) } \\
\hline 0 & $1(9)$ \\
\hline 1 & $8(73)$ \\
\hline 2 & $2(18)$ \\
\hline \multicolumn{2}{|l|}{ Comorbidities, n (\%) } \\
\hline Diabetes mellitus & 0 \\
\hline Hypertension & $3(27)$ \\
\hline Hyperlipidemia & $3(27)$ \\
\hline Smoking history & $1(9)$ \\
\hline Alcohol consumption & $2(18)$ \\
\hline \multicolumn{2}{|l|}{ Glycemia-interfering treatments, $\mathrm{n}(\%)$} \\
\hline Corticosteroids & $7(64)$ \\
\hline Parenteral nutrition & $2(18)$ \\
\hline Use of a gastrostomy & $2(18)$ \\
\hline Oral nutritional supplements & $5(45)$ \\
\hline \multicolumn{2}{|l|}{ Primary tumour site, $\mathrm{n}(\%)$} \\
\hline Oropharynx & $5(45)$ \\
\hline Hypopharynx & $3(27)$ \\
\hline Oral cavity & $3(27)$ \\
\hline \multicolumn{2}{|l|}{ HPV status, n (\%) } \\
\hline HPV negative & $6(55)$ \\
\hline HPV positive & $2(18)$ \\
\hline x]/jax/output/CommonHTML/fonts/TeX/fontdata.js & $3(27)$ \\
\hline
\end{tabular}




\begin{tabular}{|lc|}
\hline Characteristics & $\mathbf{N}=\mathbf{1 1}$ \\
\hline Type of recurrence, $\mathrm{n}(\%)$ & $3(27)$ \\
\hline Locoregional recurrence only & $6(55)$ \\
\hline Distant metastases only & $2(18)$ \\
\hline Both & $2[2-5]$ \\
\hline Number of prior lines of therapy in the recurrent and/or metastatic setting \\
\hline Median [range] & $1(9)$ \\
\hline PI3K pathway alterations, $\mathrm{n}(\%)$ & $1(9)$ \\
\hline PIK3CA mutation and PTEN loss & $7(64)$ \\
\hline PTEN loss & $2(18)$ \\
\hline No alteration & \\
\hline Not done & \\
\hline
\end{tabular}

Patients received a median of one cycle of copanlisib [range: 0.3-4] (Table 2). Patients received a median of three infusions of copanlisib [range: 1-12], and a median dose of $90 \mathrm{mg}$ [range: 30-360]. Patients received a median of less than one cycle of cetuximab [range: $0.3-3$ ]. Patients received a median of two infusions of cetuximab [range: 1-11], and a median dose of $650 \mathrm{mg}$ [range: 400-2900].

Table 2

Number of infusions, cycles, and cumulative dose of copanlisib by dose level and cetuximab

\begin{tabular}{|lllllllllll|}
\hline & \multicolumn{3}{c}{ Number of infusions } & \multicolumn{3}{c|}{ Number of cycles } & \multicolumn{3}{c|}{ Cumulative dose, $\mathrm{mg}$} \\
\cline { 2 - 11 } & Median & Min & Max & Median & Min & Max & Median & Min & Max \\
\hline Copanlisib & 1 & 1 & 2 & $<1$ & $<1$ & 1 & 45 & 45 & 90 \\
\hline $45 \mathrm{mg}$ & 7 & 1 & 12 & 2 & $<1$ & 4 & 210 & 30 & 360 \\
\hline $30 \mathrm{mg}$ & 2 & 1 & 11 & $<1$ & $<1$ & 3 & 650 & 400 & 2900 \\
\hline Cetuximab & 2 & & & & & & & & \\
\hline
\end{tabular}

\section{Safety and tolerability}

Thirty-eight treatment-related AEs were observed, including 15 grade 1 AEs (39.5\%), 13 grade 2 AEs (34.2\%), and 10 grade $3 \mathrm{AEs}$ (26.3\%) (Table 3). No treatment-related death occurred during the study. 
Table 3

Summary of cetuximab and copanlisib-related adverse events by dose level

\begin{tabular}{|c|c|c|c|c|c|}
\hline \multirow[t]{2}{*}{ Adverse drug reactions n (\%) } & \multirow[t]{2}{*}{ Grade $^{a}$} & \multicolumn{2}{|l|}{$\begin{array}{l}\text { Dose level } 1 \\
(\mathrm{~N}=3)\end{array}$} & \multicolumn{2}{|c|}{$\begin{array}{l}\text { Dose level - } 1 \\
(\mathrm{~N}=8)\end{array}$} \\
\hline & & Cetuximab & Copanlisib & Cetuximab & Copanlisib \\
\hline \multicolumn{6}{|l|}{ Investigations } \\
\hline \multirow[t]{3}{*}{ Hyperglycemia } & 1 & & & & $1(13)^{9}$ \\
\hline & 2 & & & & $2(25)^{9}$ \\
\hline & 3 & & $2(67)^{*}$ & & $2(25)^{\S}$ \\
\hline $\begin{array}{l}\text { Aspartate aminotransferase } \\
\text { increase }\end{array}$ & 1 & & & & $1(13)$ \\
\hline Creatinine increase & 1 & & & & $1(13)$ \\
\hline Hypercalcemia & 1 & & & $1(13)$ & \\
\hline Hypokalemia & 1 & & & $1(13)$ & \\
\hline Hypomagnesemia & 2 & & & $1(13)$ & \\
\hline \multicolumn{6}{|l|}{ Vascular disorders } \\
\hline \multirow[t]{2}{*}{ Hypertension } & 2 & & & & $1(13)$ \\
\hline & 3 & & $2(67)$ & & $2(25)$ \\
\hline \multicolumn{6}{|l|}{ Blood and lymphatic disorders } \\
\hline \multirow[t]{2}{*}{ Anemia } & 2 & & & & $1(13)$ \\
\hline & 3 & & & & $1(13)$ \\
\hline Leucopenia & 1 & & & & $1(13)$ \\
\hline \multirow[t]{2}{*}{ Lymphopenia } & 2 & & & & $1(13)$ \\
\hline & 3 & & & & $1(13)$ \\
\hline Eosinophil count increase & 1 & & & & $1(13)$ \\
\hline
\end{tabular}

aAdverse events classified and graded using National Cancer Institute Common Terminology Criteria for Adverse Events version 4.03

*Patients not premedicated with metformin

SPatient premedicated with metformin $500 \mathrm{mg}$ on the day of the copanlisib infusion

Loading [MathJax]/jax/output/CommonHTML/fonts/TeX/fontdata.js day of the copanlisib infusion 


\begin{tabular}{|c|c|c|c|}
\hline Adverse drug reactions $\mathrm{n}(\%)$ & Grade $^{a}$ & $\begin{array}{l}\text { Dose level } 1 \\
(\mathrm{~N}=3)\end{array}$ & $\begin{array}{l}\text { Dose level - } 1 \\
(\mathrm{~N}=8)\end{array}$ \\
\hline \multicolumn{4}{|l|}{ Gastrointestinal disorders } \\
\hline Constipation & 1 & & $1(13)$ \\
\hline \multirow[t]{2}{*}{ Diarrhea } & 1 & & $1(13)$ \\
\hline & 2 & & $1(13)$ \\
\hline Nausea & 1 & & $1(13)$ \\
\hline Vomiting & 1 & & $1(13)$ \\
\hline \multicolumn{4}{|l|}{ General disorders } \\
\hline \multirow[t]{2}{*}{ Asthenia } & 1 & & $1(13)$ \\
\hline & 2 & $1(33)$ & $2(25)$ \\
\hline \multicolumn{4}{|l|}{ Skin disorders } \\
\hline Folliculitis & 1 & & $1(13)$ \\
\hline Periorbital erythema & 1 & & $1(13)$ \\
\hline Pruritis & 1 & & $1(13)$ \\
\hline Acneiform rash & 2 & & $2(25)$ \\
\hline Paronychia & 2 & & $1(13)$ \\
\hline \multicolumn{4}{|c|}{$\begin{array}{l}{ }^{a} \text { Adverse events classified and graded using National Cancer Institute Common Terminology Criter } \\
\text { for Adverse Events version } 4.03\end{array}$} \\
\hline \multicolumn{4}{|c|}{ *Patients not premedicated with metformin } \\
\hline \multicolumn{4}{|c|}{ §Patient premedicated with metformin $500 \mathrm{mg}$ on the day of the copanlisib infusion } \\
\hline
\end{tabular}

At the initial dose level of $45 \mathrm{mg}$, two patients out of three (67\%) experienced a grade 3 hyperglycemia during Cycle 1 that met the DLT criteria. The next eight patients were treated at dose level -1 with copanlisib $30 \mathrm{mg}$. Because the first patient of that dose level also experienced a transient grade 3 hyperglycemia, the next two patients were premedicated with metformine $500 \mathrm{mg}$ starting on the day of the copanlisib injection either at Day 15 or at Day 1 of the first cycle. The patient who was premedicated with metformine $500 \mathrm{mg}$ at Day 15 still experienced a transient grade 3 hyperglycemia, and metformine premedication was therefore increased to $1000 \mathrm{mg}$ in the next five patients. No DLTs were met at the dose level of copanlisib $30 \mathrm{mg}$. 
Transient grade 3 adverse events that did not meet the DLT criteria were reported. Among the three patients treated at the dose level of $45 \mathrm{mg}$, two patients (67\%) experienced a grade 3 hypertension. Among the eight patients treated at the dose level of $30 \mathrm{mg}$, the two first patients (25\%) experienced a transient grade 3 hyperglycemia. A grade 3 hypertension was reported in two patients (25\%), a grade 3 anemia in one patient (12.5\%), and a grade 3 lymphopenia in one patient (12.5\%). Premedication with metformine $1000 \mathrm{mg}$ significantly correlated with low blood glucose levels compared to patients without premedication ( $p=0.026)$ (Fig. 2).

Across the entire cohort, two patients (18\%) experienced a grade 2 acneiform rash, which was the most common AE associated with cetuximab. Eight patients (73\%) experienced grade 4 AEs unrelated to copanlisib and cetuximab, including thrombopenia, oral haemorrhage, general physical health deterioration, cholestasis, device-related infection, lung abscess, septicemia, and hypokalemia in one patient each (9\%).

Permanent treatment discontinuation was caused by copanlisib-related grade 3 hyperglycemia in three patients $(27 \%)$, disease progression in three patients $(27 \%)$, grade 2 septicemia in one patient $(9 \%)$, grade 4 oral haemorrhage in one patient (9\%), grade 3 respiratory failure in one patient $(9 \%)$, lack of clinical benefit after four cycles of copanlisib in one patient (9\%), and death in one patient (9\%).

\section{Pharmacokinetics}

From the 11 patients investigated, 77 time-blood samples were available for analysis (Table 4). Following a single copanlisib infusion at dose of $45 \mathrm{mg}$ (Cycle 1, Day 1), the mean maximum plasma concentration $\left(C_{\max }\right)$ reached $242 \mu \mathrm{g} / \mathrm{L}$ [range: $136-348$ ] at a mean time $\left(T_{\max }\right)$ of 1.01 hour [range: $0.95-1.07$ ]. At the dose level of $30 \mathrm{mg}$ (Cycle 1, Day 1), the mean $\mathrm{C}_{\max }$ reached $158 \mu \mathrm{g} / \mathrm{L}$ [range: 82-234]. The main covariate effect was related to body weight, which influenced the clearance and central volume distribution of copanlisib. The central volume of distribution was higher than the circulating blood volume in addition with a large volume of deep compartment, suggesting that copanlisib had a large tissue diffusion. This result was also corroborated by similar $\mathrm{C}_{\max }$ on Days 1 and 15 (the mean $\mathrm{C}_{\max }$ reached $193 \mu \mathrm{g} / \mathrm{L}$ [range: 79-307] at the dose of copanlisib $30 \mathrm{mg}$ on Day 15 of Cycle 1). 
Table 4

Copanlisib pharmacokinetics parameters by individual approach

\begin{tabular}{|c|c|c|c|c|c|c|}
\hline \multirow[t]{2}{*}{ Cycle } & \multirow[t]{2}{*}{ Dose } & \multirow{2}{*}{$\begin{array}{l}\text { No. of } \\
\text { samples }\end{array}$} & \multicolumn{4}{|c|}{ Mean (standard deviation) } \\
\hline & & & $t_{1 / 2}(h)$ & $\mathrm{T}_{\max }(\mathrm{h})$ & $\begin{array}{l}C_{\max } \\
(\mu \mathrm{g} / \mathrm{L})\end{array}$ & $\begin{array}{l}\text { AUC }_{0-\text { last }} \\
\left(\mu \mathrm{g} / \mathrm{L}^{*}\right)\end{array}$ \\
\hline Cycle 1 Day 1 & $\begin{array}{l}45 \\
\mathrm{mg}\end{array}$ & 15 & $\begin{array}{l}13.7 \\
(2.91)\end{array}$ & $\begin{array}{l}1.01 \\
(0.06)\end{array}$ & $242(106)$ & $1393(455)$ \\
\hline Cycle 1 Day 1 & $\begin{array}{l}30 \\
\mathrm{mg}\end{array}$ & 39 & $\begin{array}{l}13.7 \\
(2.91)\end{array}$ & $\begin{array}{l}1.01 \\
(0.06)\end{array}$ & $158(75.7)$ & $833(304)$ \\
\hline $\begin{array}{l}\text { Cycle } 1 \text { Day } \\
15\end{array}$ & $\begin{array}{l}30 \\
\mathrm{mg}\end{array}$ & 23 & $\begin{array}{l}13.7 \\
(2.91)\end{array}$ & $\begin{array}{l}1.01 \\
(0.06)\end{array}$ & $193(114)$ & $3213(680)$ \\
\hline
\end{tabular}

\section{Efficacy}

Median follow-up was 6.0 months [range: $2.4-10.8$ ]. In the overall study population, eight out of the 11 patients (72.7\%) were evaluable for response according to RECIST1.1. Three patients were not evaluable because of early death. No complete or partial response was observed. Four patients (50\%) experienced a disease stabilisation, including one patient with both a PTEN loss and a PIK3CA mutation (Fig. 3). The median duration of disease stabilization was 2.9 months [range: 1.1-3.8].

In the overall study population, the median PFS was 2.66 months (95\% confidence interval [Cl]: $1.28-$ 4.24). Median OS was 6.01 months (95\% Cl: 1.97-11.6) (Supplementary Fig. 1).

The $\mathrm{C}_{\max }$ and $\mathrm{AUC}_{0 \text { - last }}$ of copanlisib did not correlate with PFS ( $\mathrm{p}=0.11$ and $\mathrm{p}=1.0$, respectively) or OS $(p=0.38$ and $p=0.51$, respectively).

\section{Discussion}

Our study established that intravenous copanlisib combined with weekly intravenous cetuximab could not be safely administered to patients with recurrent and/or metastatic HNSCC without a premedication with metformin because of hyperglycemia. Although a premedication with metformin would have allowed to re-escalate, the sponsor decided to stop the study given the poor tolerance and limited efficacy. Therefore, both the maximum tolerated dose and the recommended phase 2 dose of the combination could not be established.

The most common copanlisib-related AEs were hyperglycemia and hypertension. The safety profile of cetuximab did not seem to be impacted by the addition of copanlisib, with common class-effect toxicities including rash and hypomagnesemia.

The overall incidence of all-grade and grade 3 hyperglycemia were $64 \%$ and $36 \%$ respectively. In clinical trials evaluating single-agent copanlisib in lymphoma patients at the dose of $60 \mathrm{mg}$, the overall 
respectively $[17,19]$. The higher incidence of grade 3 hyperglycemia reported in our study might be related to our HNSCC patient population. Due to cancer-or treatment-related dysphagia, most patients were fed with means increasing the risk of hyperglycemia, including the use of a gastrostomy, parenteral nutrition, and oral nutritional supplements. In addition, most of patients were receiving corticosteroids that is known to increase glycemia. Hyperglycemia is a recognized on-target effect of p110a inhibition, given that $1110 a$ is a critical lipid kinase required for insulin signaling in two key cell types, including adipocytes and myotubes $[20,21]$.

The incidences of all-grade (46\%) and grade $3(36 \%)$ hypertension were also higher than reported in clinical trials evaluating single-agent copanlisib at the dose of $60 \mathrm{mg}[17,19]$. These differences can be explained by the high rate of patients with hypertension at baseline in our study (27\%). Furthermore, HNSCC patients often suffer from cardiovascular comorbidities due to tobacco and alcohol consumption [22]. Gastrointestinal toxicities remained low relative to orally administered PI3K inhibitors [23, 24], presumably due to the intravenous route of administration, and the absence of a first-pass metabolism. In addition, a lower incidence of diarrhea (18\%) and transaminases increase (9\%) was observed in our study as compared with those reported in single-agent studies of copanlisib at the dose of $60 \mathrm{mg}[17,19]$.

Pharmacokinetics parameters of copanlisib combined with cetuximab were consistent with those reported for weight-based dosing copanlisib monotherapy [16], including a short $T_{\max }$ and a long $t_{1 / 2}$. Copanlisib had a large tissue diffusion with similar $C_{\max }$ on Days 1 and 15 . Given the lack of significant accumulation, our results suggest no pharmacokinetics interaction between copanlisib and cetuximab. This was expected since the metabolism of copanlisib is mediated via CYP3A4/5 (>90\%) and to a minor extent via CYP1A1 (<10\%) [25], and cetuximab is a monoclonal antibody that is degraded by macrophages without any liver metabolism. Copanlisib pharmacokinetics was dose proportional.

Four out of eight evaluable patients achieved disease stabilization according to RECIST1.1, but no objective responses were observed. The limited efficacy observed in our study might be explained by several factors. First, none of the patients were exposed to the recommended phase II dose of copanlisib as single agent. Given that all patients had progressed on cetuximab before, it is unlikely that a suboptimal dose of copanlisib might have been able to produce antitumor activity in combination with cetuximab. Second, our patient population was heavily pretreated with a poor prognosis as exemplified by the fact that three patients died within two months following their entry in the study. Despite the suboptimal treatment received, the observed median overall survival (6.01 months) and median progression-free survival (2.66 months) were in line with the results obtained in a randomized phase II clinical trial evaluating PX-866, an irreversible oral PI3K inhibitor, in combination with cetuximab in a similar patient population [26].

In summary, copanlisib combined with cetuximab demonstrated unfavorable toxicity and limited efficacy in heavily pretreated recurrent and/or metastatic HNSCC patients. The use of a premedication with metformin might have allowed to increase the dose of copanlisib to a potentially effective dose. The 
inclusion of a larger patient population would have allowed to evaluate a potential differential effect between patients with tumors harboring a PIK3CA or PTEN alteration versus the others.

\section{Declarations}

\section{Compliance with ethical standards}

\section{Conflicts of interest}

CLT participated in advisory boards from MSD, BMS, Merck Serono, Astra Zeneca, Celgene, Seattle Genetics, Roche, Novartis, Rakuten, Nanobiotix, and GSK. JG participated in advisory boards from Astra Zeneca, BMS, Innate Pharma, Merck Serono, Roche, and as invited speaker for Merck SD and Merck Serono. All other authors have no conflict of interest to disclose.

\section{Ethical approval}

All procedures performed in studies involving human participants were in accordance with the ethical standards of the institutional and/or national research committee and with the 1964 Helsinki declaration and its later amendments or comparable ethical standards.

\section{Informed consent}

Informed consent was obtained from all individual participants included in the study.

\section{Author declarations}

\section{Funding}

The study was funded by Bayer.

\section{Data availability}

The datasets generated during and/or analysed during the current study are available from the corresponding author on reasonable request.

\section{Authors' contribution statement}

CLT, MA, KR, JG, and MC wrote the protocol. CLT, NI, ESB, FR, EB, MA, and DV contributed to the recruitment and treatment of patients in the trial. All authors contributed to the acquisition of data, the analysis, and the interpretation of data. CLT and GM designed the figures and wrote the first draft of the manuscript. All authors reviewed the manuscript before submission.

\section{Acknowledgements}


We thank the participating patients, the UNICANCER Head and Neck research team, Marta Jimenez, Celia Dupain, and Linda Larbi Cherif.

\section{References}

1. Bray F, Ferlay J, Soerjomataram I et al (2018) Global cancer statistics 2018: GLOBOCAN estimates of incidence and mortality worldwide for 36 cancers in 185 countries. CA Cancer J Clin 68:394-424. https://doi.org/10.3322/caac.21492

2. Machiels J-P, René Leemans C, Golusinski W et al (2020) Squamous cell carcinoma of the oral cavity, larynx, oropharynx and hypopharynx: EHNS-ESMO-ESTRO Clinical Practice Guidelines for diagnosis, treatment and follow-up. Ann Oncol 31:1462-1475. https://doi.org/10.1016/j.annonc.2020.07.011

3. Leeman JE, Li J-G, Pei X et al (2017) Patterns of Treatment Failure and Postrecurrence Outcomes Among Patients With Locally Advanced Head and Neck Squamous Cell Carcinoma After Chemoradiotherapy Using Modern Radiation Techniques. JAMA Oncol 3:1487-1494. https://doi.org/10.1001/jamaoncol.2017.0973

4. Chow LQM (2020) Head and Neck Cancer. N Engl J Med 382:60-72. https://doi.org/10.1056/NEJMra1715715

5. Ferris RL, Blumenschein G, Fayette J et al (2016) Nivolumab for Recurrent Squamous-Cell Carcinoma of the Head and Neck. N Engl J Med 375:1856-1867. https://doi.org/10.1056/NEJMoa1602252

6. Cohen EEW, Soulières D, Le Tourneau C et al (2019) Pembrolizumab versus methotrexate, docetaxel, or cetuximab for recurrent or metastatic head-and-neck squamous cell carcinoma (KEYNOTE-040): a randomised, open-label, phase 3 study. Lancet 393:156-167. https://doi.org/10.1016/S01406736(18)31999-8

7. Burtness B, Harrington KJ, Greil R et al (2019) Pembrolizumab alone or with chemotherapy versus cetuximab with chemotherapy for recurrent or metastatic squamous cell carcinoma of the head and neck (KEYNOTE-048): a randomised, open-label, phase 3 study. Lancet 394:1915-1928. https://doi.org/10.1016/S0140-6736(19)32591-7

8. Vermorken JB, Mesia R, Rivera F et al (2008) Platinum-based chemotherapy plus cetuximab in head and neck cancer. N Engl J Med 359:1116-1127. https://doi.org/10.1056/NEJMoa0802656

9. Guigay J, Aupérin A, Fayette J et al (2021) Cetuximab, docetaxel, and cisplatin versus platinum, fluorouracil, and cetuximab as first-line treatment in patients with recurrent or metastatic head and neck squamous-cell carcinoma (GORTEC 2014-01 TPExtreme): a multicentre, open-label, randomised, phase 2 trial. Lancet Oncol 22:463-475. https://doi.org/10.1016/S14702045(20)30755-5

10. Liu P, Cheng H, Roberts TM, Zhao JJ (2009) Targeting the phosphoinositide 3-kinase pathway in cancer. Nat Rev Drug Discov 8:627-644. https://doi.org/10.1038/nrd2926

11. Lui VWY, Hedberg ML, Li H et al (2013) Frequent mutation of the PI3K pathway in head and neck cancer defines predictive biomarkers. Cancer Discov 3:761-769. https://doi.org/10.1158/2159- 
8290.CD-13-0103

12. Cancer Genome Atlas Network (2015) Comprehensive genomic characterization of head and neck squamous cell carcinomas. Nature 517:576-582. https://doi.org/10.1038/nature14129

13. Rebucci M, Peixoto $P$, Dewitte A et al (2011) Mechanisms underlying resistance to cetuximab in the HNSCC cell line: role of AKT inhibition in bypassing this resistance. Int J Oncol 38:189-200

14. D'Amato V, Rosa R, D'Amato C et al (2014) The dual PI3K/mTOR inhibitor PKI-587 enhances sensitivity to cetuximab in EGFR-resistant human head and neck cancer models. Br J Cancer 110:2887-2895. https://doi.org/10.1038/bjc.2014.241

15. Soulières D, Faivre S, Mesía R et al (2017) Buparlisib and paclitaxel in patients with platinumpretreated recurrent or metastatic squamous cell carcinoma of the head and neck (BERIL-1): a randomised, double-blind, placebo-controlled phase 2 trial. Lancet Oncol 18:323-335. https://doi.org/10.1016/S1470-2045(17)30064-5

16. Patnaik A, Appleman LJ, Tolcher AW et al (2016) First-in-human phase I study of copanlisib (BAY 806946), an intravenous pan-class I phosphatidylinositol 3-kinase inhibitor, in patients with advanced solid tumors and non-Hodgkin's lymphomas. Ann Oncol 27:1928-1940. https://doi.org/10.1093/annonc/mdw282

17. Dreyling M, Santoro A, Mollica L et al (2020) Long-term safety and efficacy of the PI3K inhibitor copanlisib in patients with relapsed or refractory indolent lymphoma: 2-year follow-up of the CHRONOS-1 study. Am J Hematol 95:362-371. https://doi.org/10.1002/ajh.25711

18. Klinghammer K, Politz O, Eder T et al (2020) Combination of copanlisib with cetuximab improves tumor response in cetuximab-resistant patient-derived xenografts of head and neck cancer. Oncotarget 11:3688-3697. https://doi.org/10.18632/oncotarget.27763

19. Dreyling M, Santoro A, Mollica L et al (2017) Phosphatidylinositol 3-Kinase Inhibition by Copanlisib in Relapsed or Refractory Indolent Lymphoma. J Clin Oncol 35:3898-3905. https://doi.org/10.1200/JC0.2017.75.4648

20. Shepherd PR, Withers DJ, Siddle K (1998) Phosphoinositide 3-kinase: the key switch mechanism in insulin signalling. Biochem J 333:471-490. https://doi.org/10.1042/bj3330471

21. Knight ZA, Gonzalez B, Feldman ME et al (2006) A pharmacological map of the PI3-K family defines a role for p110alpha in insulin signaling. Cell 125:733-747.

https://doi.org/10.1016/j.cell.2006.03.035

22. Bøje CR, Dalton SO, Primdahl H et al (2014) Evaluation of comorbidity in 9388 head and neck cancer patients: a national cohort study from the DAHANCA database. Radiother Oncol 110:91-97. https://doi.org/10.1016/j.radonc.2013.11.009

23. Flinn IW, Kahl BS, Leonard JP et al (2014) Idelalisib, a selective inhibitor of phosphatidylinositol 3kinase- $\delta$, as therapy for previously treated indolent non-Hodgkin lymphoma. Blood 123:3406-3413. https://doi.org/10.1182/blood-2013-11-538546

24. Gopal AK, Kahl BS, de Vos S et al (2014) PI3Kס inhibition by idelalisib in patients with relapsed Loading [MathJax]/jax/output/CommonHTML/fonts/TeX/fontdata.js ittps://doi.org/10.1056/NEJMoa1314583 
25. Drug Approval Package: ALIQOPA (copanlisib). https://www.accessdata.fda.gov/drugsatfda_docs/nda/2017/2099360rig1_toc.cfm. Accessed 1 Jun 2021

26. Jimeno A, Shirai K, Choi M et al (2015) A randomized, phase II trial of cetuximab with or without PX866 , an irreversible oral phosphatidylinositol 3-kinase inhibitor, in patients with relapsed or metastatic head and neck squamous cell cancer. Ann Oncol 26:556-561. https://doi.org/10.1093/annonc/mdu574

\section{Figures}




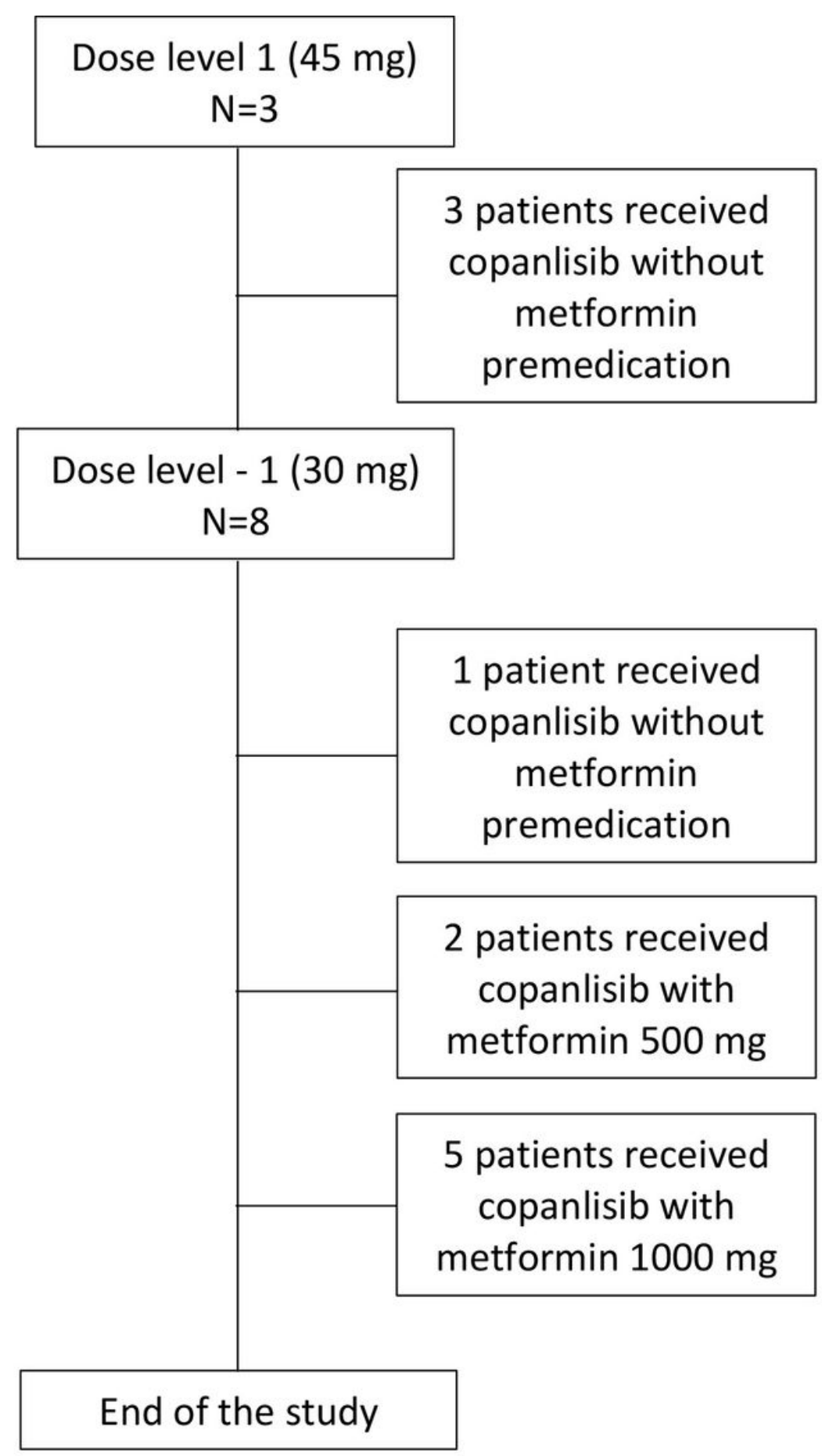

Fig 1 Study flowchart

Figure 1

Study flowchart 


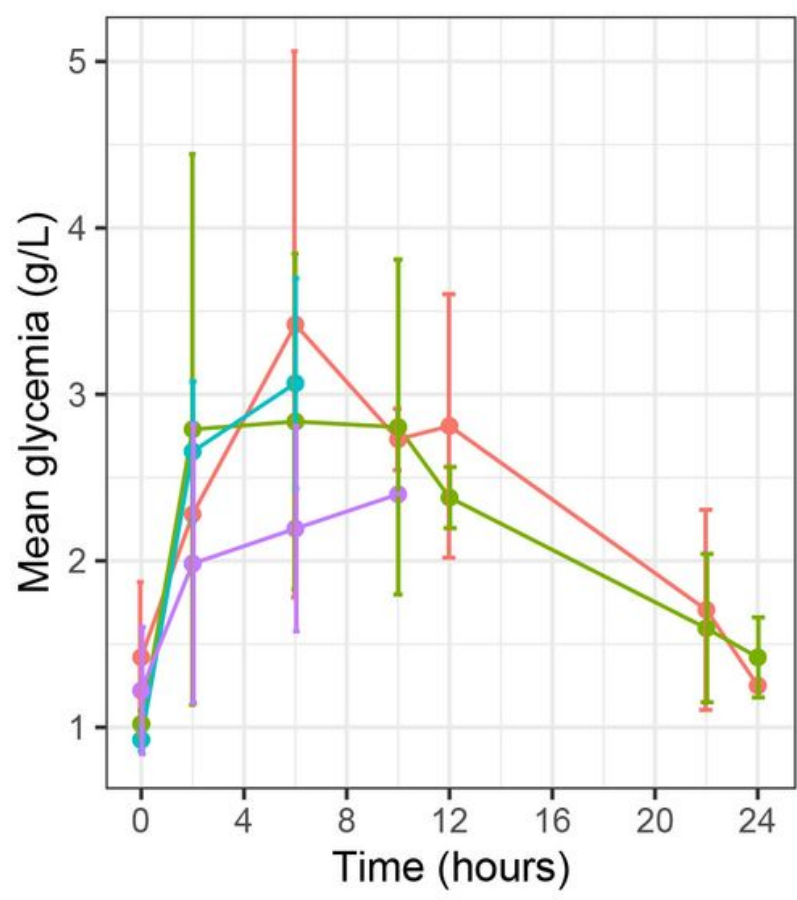

-C Copanlisib $45 \mathrm{mg}$ without metformin premedication ( $\mathrm{N}=3$ )

$\rightarrow$ Copanlisib $30 \mathrm{mg}$ without metformin premedication ( $\mathrm{N}=1)$

$\rightarrow$ Copanlisib $30 \mathrm{mg}$ with metformin $500 \mathrm{mg}$ premedication ( $\mathrm{N}=2$ )

$\rightarrow$ Copanlisib $30 \mathrm{mg}$ with metformin $1000 \mathrm{mg}$ premedication $(\mathrm{N}=5)$

\section{Figure 2}

Mean glycemia $(\mathrm{g} / \mathrm{L})$ by dose of copanlisib and metformine uptake at Cycle 1 Day 1

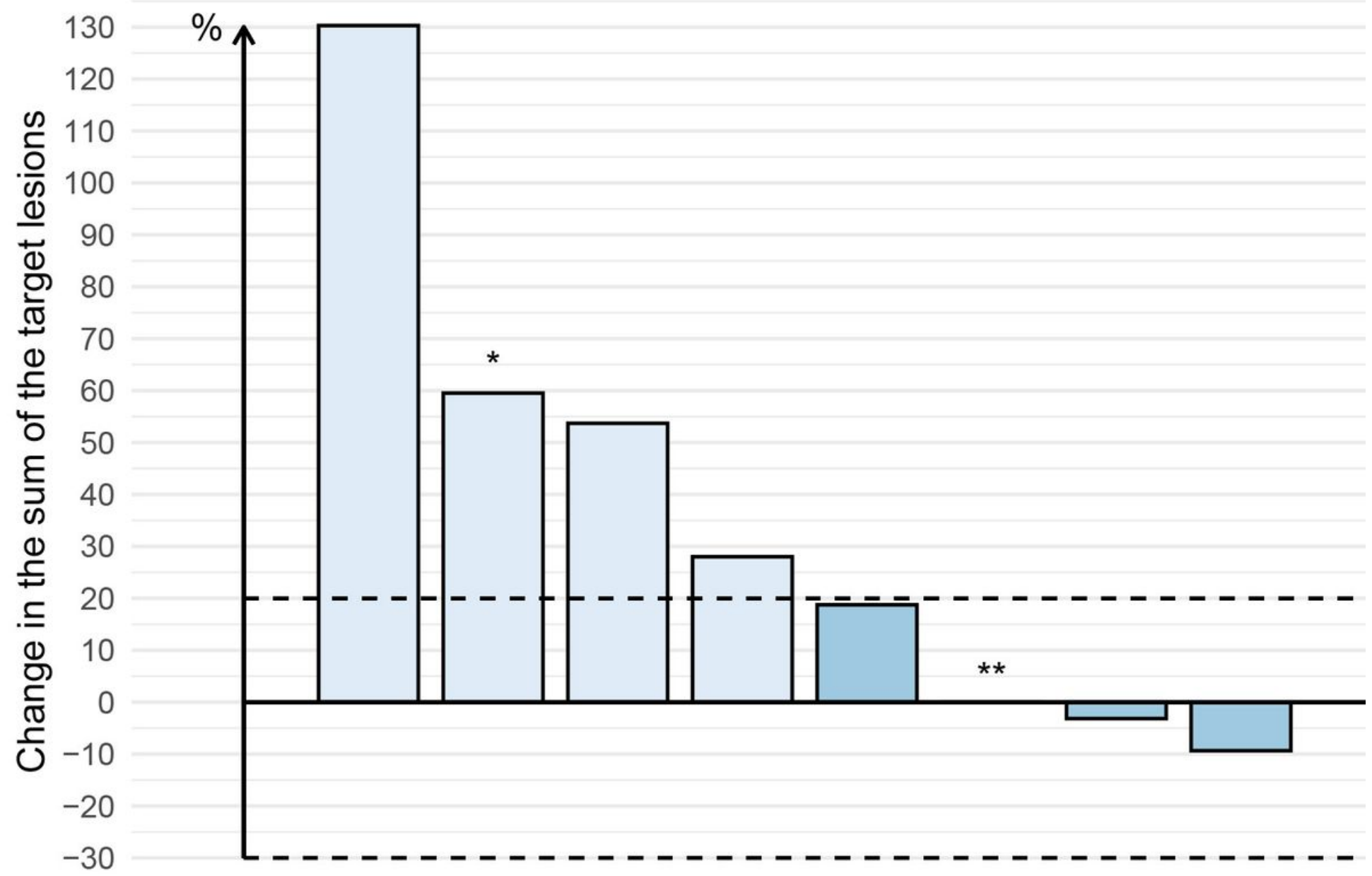




\section{Figure 3}

Waterfall plot representing the best change in the sum of the target lesions according to RECIST1.1 Each bar represents one patient. The best change in target lesion size could not be determined in three patients. * PTEN loss ** PTEN loss and PIK3CA mutation

\section{Supplementary Files}

This is a list of supplementary files associated with this preprint. Click to download.

- SupplementaryFigure1.pdf

- SupplementaryMaterialsandMethods.docx 